OPEN ACCESS

Edited by:

Janos G. Filep,

Université de Montréal, Canada

Reviewed by:

Bernd Rosenkranz,

Stellenbosch University,

South Africa

Sahana Holla,

National Cancer Institute

(NIH), USA

Martin Rottenberg,

Karolinska Institutet, Sweden

*Correspondence:

Jon S. Friedland

j.friedland@imperial.ac.uk

tThese authors are joint first authors; these authors have contributed

equally to this work.

Specialty section:

This article was submitted to

Molecular Innate Immunity,

a section of the journal

Frontiers in Immunology

Received: 24 February 2017 Accepted: 08 May 2017

Published: 24 May 2017

Citation:

Moores RC, Brilha S, Schutgens F, Elkington PT and Friedland JS (2017)

Epigenetic Regulation of Matrix

Metalloproteinase-1 and -3

Expression in Mycobacterium tuberculosis Infection.

Front. Immunol. 8:602.

doi: 10.3389/fimmu.2017.00602

\section{Epigenetic Regulation of Matrix Metalloproteinase-1 and -3 Expression in Mycobacterium tuberculosis Infection}

\author{
Rachel C. Moores ${ }^{1 \dagger}$, Sara Brilha ${ }^{1,2 t}$, Frans Schutgens ${ }^{1}$, Paul T. Elkington ${ }^{1,3}$ \\ and Jon S. Friedland ${ }^{1 *}$
}

${ }^{1}$ Section of Infectious Diseases and Immunity, Imperial College London, London, UK, ${ }^{2}$ Centre for Inflammation and Tissue Repair, Respiratory Medicine, University College London, London, UK, ${ }^{3}$ National Institute of Health Research (NIHR) Respiratory Biomedical Research Unit, Faculty of Medicine, University of Southampton, Southampton, UK

In pulmonary tuberculosis (TB), the inflammatory immune response against Mycobacterium tuberculosis (Mtb) is associated with tissue destruction and cavitation, which drives disease transmission, chronic lung disease, and mortality. Matrix metalloproteinase (MMP)-1 is a host enzyme critical for the development of cavitation. MMP expression has been shown to be epigenetically regulated in other inflammatory diseases, but the importance of such mechanisms in Mtb-associated induction of MMP-1 is unknown. We investigated the role of changes in histone acetylation in Mtb-induced MMP expression using inhibitors of histone deacetylases (HDACs) and histone acetyltransferases $(\mathrm{HAT}), \mathrm{HDAC}$ siRNA, promoter-reporter constructs, and chromatin immunoprecipitation assays. Mtb infection decreased Class I HDAC gene expression by over $50 \%$ in primary human monocyte-derived macrophages but not in normal human bronchial epithelial cells (NHBEs). Non-selective inhibition of HDAC activity decreased MMP-1/-3 expression by Mtb-stimulated macrophages and NHBEs, while class I HDAC inhibition increased MMP-1 secretion by Mtb-stimulated NHBEs. MMP-3 expression, but not MMP-1, was downregulated by siRNA silencing of HDAC1. Inhibition of HAT activity also significantly decreased MMP-1/-3 secretion by Mtb-infected macrophages. The MMP-1 promoter region between $-2,001$ and $-2,942$ base pairs from the transcriptional start site was key in control of Mtb-driven MMP-1 gene expression. Histone $\mathrm{H} 3$ and $\mathrm{H} 4$ acetylation and RNA Pol II binding in the MMP-1 promoter region were increased in stimulated NHBEs. In summary, epigenetic modification of histone acetylation via HDAC and HAT activity has a key regulatory role in Mtb-dependent gene expression and secretion of MMP-1 and -3, enzymes which drive human immunopathology. Manipulation of epigenetic regulatory mechanisms may have potential as a host-directed therapy to improve outcomes in the era of rising TB drug resistance.

Keywords: Mycobacterium tuberculosis, matrix metalloproteinases, histone deacetylases, histone acetyltransferases, epigenetics 


\section{INTRODUCTION}

Tuberculosis (TB) remains a major global health problem, with 10.4 million new cases and 1.8 million deaths per year (1). The rapid emergence of widespread drug resistance necessitates new strategies to improve the efficacy of treatment in TB, both to decrease transmission and to improve patient outcomes. Ideally, such therapies will shorten the duration of therapy, which is currently a minimum of 6 months and may be years in drugresistant disease. Host-directed therapies are increasingly of interest in TB (2).

The primary site of Mycobacterium tuberculosis (Mtb) infection is the lung, and pulmonary disease is characterized by granulomatous inflammation with destruction of lung parenchyma. The outcome of infection is very variable between hosts, and the factors determining this are not well understood, although host genetics and innate immune responses are important determinants of disease $(3,4)$. Matrix metalloproteinases (MMPs) are zinc-dependent endopeptidases, which have key roles in tissue repair and in diseases characterized by inflammatory tissue destruction such as emphysema (5). MMPs are key mediators of inflammatory cell migration, and modulators of chemokine and cytokine signaling $(6,7)$. MMP activity is strongly implicated in the immunopathogenesis of TB. Our group and others demonstrated the involvement of MMP-1, the major human collagenase, and its activator MMP-3 (stromelysin-1) in driving pathology in pulmonary TB (8-10). MMPs are secreted by Mtb-infected monocytes and macrophages, and also by uninfected stromal cells stimulated via intercellular networks (11). Epigenetic mechanisms are emerging as major regulators of MMP activity in non-infectious diseases $(12,13)$, including chronic lung diseases such as asthma and COPD (14), but their role in MMP expression in TB is less established.

Epigenetic regulation encompasses all chromosomal modifications that alter gene expression without altering the nucleotide sequence of coding DNA $(15,16)$. Eukaryotic DNA is packaged as chromatin around octamers of histone proteins, which contain globular domains and negatively charged tails. These are subject to extensive post-translational modification, including acetylation of highly conserved lysine residues. Acetylation of histones $\mathrm{H} 3$ and H4, carried out by Histone acetyltransferases (HATs), is associated with increased gene transcription (17). Conversely, acetyl groups are removed by the histone deacetylases (HDACs), which are divided into four classes. The Class I HDACs (1, 2, 3 , and 8 ) are ubiquitously expressed, whereas Class II HDACs (such as HDAC 4 and 5) are selectively expressed in different tissues. HDAC activity is usually associated with silencing of gene expression $(18,19)$. However, this is not uniformly the case and opposite regulation may occur. For example, HDAC inhibition reduced MMP-9 gene expression in cancer cell lines resulting in a less invasive phenotype (20).

The epigenetic mechanisms regulating inflammatory immune responses in TB are an emerging field. Altered miRNA expression in serum and sputum from TB patients compared to controls has been shown, and potential biomarkers for diagnosis have been identified (21). A growing body of evidence exists to support the importance of epigenetic mechanisms in other respiratory infections, for example, altered DNA methylation patterns in asthma patients versus healthy controls have been implicated in the pathogenesis of rhinovirus infection (22). Similarly, altered DNA (cytosine-5-)-methyltransferase-1 (DMT-1) expression in nasal epithelial cells from smokers was identified as a possible mechanism of increased susceptibility to influenza (23). In vitro studies of airway epithelial cells demonstrated increased HDAC2 expression and decreased histone acetylation in respiratory syncytial virus (RSV)-infected cells, while chemical HDAC inhibition restricted RSV replication (24). In the current study, we have investigated whether epigenetic modifications, specifically histone acetylation/deacetylation, regulated the characteristic TB-associated expression of MMP-1 and MMP-3 by monocytederived macrophages and normal human bronchial epithelial cells (NHBEs), thereby augmenting TB immunopathology. The role of histone acetylation in induction of MMP-1/-3 expression was specifically investigated, since this dynamic epigenetic mark is associated with transcriptional activation. We demonstrate that Mtb infection alters macrophage Class I HDAC expression and that MMP-1 expression induced by Mtb is sensitive to HDAC/ HAT inhibition. In addition, increased histone acetylation was seen at MMP- 1 and -3 promoter regions compared with unstimulated cells, specifically in the region $-2,001$ to $-2,942 \mathrm{bp}$ of the MMP-1 promoter, which contains key inducible sites activated in Mtb-stimulated cells.

\section{MATERIALS AND METHODS}

\section{Reagents and Antibodies}

Trichostatin A(TSA) waspurchased from Sigma-Aldrich (Gillingham, UK), CBHA, HAT inhibitor II and Anacardic acid (AA) from Calbiochem (Millipore, Watford, UK), and MS-275 from Enzo Life Sciences (Exeter, UK). Primary rabbit anti-human acetyl-histone H3 and acetyl-histone $\mathrm{H} 4$ (Millipore) were used for chromatin immunoprecipitation. Primary mouse anti-human HDAC4 and anti-HDAC7 were used for Western blot and HRP-linked goat anti-rabbit IgG and goat anti-mouse (all from Cell Signalling, Hertfordshire, UK) were used as secondary antibodies. All other reagents were purchased from Sigma-Aldrich unless otherwise stated.

\section{Mtb Culture}

Mycobacterium tuberculosis strain $\mathrm{H} 37 \mathrm{Rv}$ was cultured from frozen stocks stored at $-80^{\circ} \mathrm{C}$ in Middlebrook $7 \mathrm{H} 9$ broth (BD Biosciences, Oxford, UK) supplemented with 10\% OADC enrichment medium (BD Biosciences), $0.2 \%$ glycerol, and $0.02 \%$ Tween 20 with agitation at $37^{\circ} \mathrm{C}$. Growth was monitored by measuring optical density (OD) using a Biowave cell density meter (WPA, Cambridge, UK). Infection experiments were performed using cultures at mid-log growth (at OD 0.55-0.65) corresponding to $1-2 \times 10^{8} \mathrm{CFU} / \mathrm{ml}$. Correlation with optical density was checked by performing colony counts in triplicate on Middlebrook 7H11 agar. Cells were infected at a multiplicity of infection (MOI) of 1 unless otherwise stated.

\section{Cell Culture}

Monocytes were adhesion-purified from leukocyte residues from healthy blood donors (NHS Blood Transfusion Service) and 
differentiated into macrophages for 4 days in RPMI 1640 (Life Technologies, Paisley, UK) supplemented with $10 \%$ fetal bovine serum (FBS) and $100 \mathrm{ng} / \mathrm{ml}$ M-CSF (R\&D Systems, Abingdon, UK). After a further $24 \mathrm{~h}$ without M-CSF, the medium was changed for M-SFM (Life Technologies) and cells were infected with Mtb H37Rv strain. Cells were pretreated with chemical inhibitors for $2 \mathrm{~h}$ prior to infection where relevant.

Primary NHBEs (Lonza, Wokingham, UK) were cultured according to the supplier's instructions in supplemented bronchial epithelial growth medium (BEGM). Medium was replaced every 3 days. Cells were subcultured at $80 \%$ confluence and used at passage 4 or 5 .

The alveolar carcinoma cell line A549 (ATCC, Middlesex, UK) was cultured in RPMI 1640 supplemented with 2 mM glutamine, $10 \mu \mathrm{g} / \mathrm{ml}$ ampicillin, and $10 \%$ FBS. For experiments, cells were seeded at $4 \times 10^{4}$ cells $/ \mathrm{cm}^{2}$ and stimulated $24 \mathrm{~h}$ later.

\section{Conditioned Medium from Mycobacterium tuberculosis-Infected Monocytes (CoMTb)}

Peripheral blood monocytes isolated as above from healthy blood donors were infected with $\mathrm{H} 37 \mathrm{Rv}$ at a MOI of 1 in RPMI without FBS for $24 \mathrm{~h}$. The culture medium was then collected and sterilized by passage through a $0.2 \mu \mathrm{M}$ Anopore syringe filter (Whatman, Brentford, UK). Paired samples of conditioned medium from uninfected monocytes (CoMCont) from the same donor were used as controls.

\section{MMP ELISAs}

Supernatants were collected at $72 \mathrm{~h}$ poststimulus, sterile filtered, and MMPs were quantified using the Duoset MMP-1 and MMP-3 ELISA kits (R\&D Systems) according to manufacturer's instructions. Lower limits of sensitivity for the Duoset kits are: 156 pg/ $\mathrm{ml}$ for MMP-1 and $31.2 \mathrm{pg} / \mathrm{ml}$ for MMP-3. Samples were run with appropriate controls and at dilutions calculated to give readings within the linear range of detection as indicated by the manufacturer.

\section{Luminex Multiplex Immunoassay}

Quantification of MMP-1, -3, -7, and -9 concentrations was performed using the Fluorokine MultiAnalyte Profiling MMP Base Kit (R\&D Systems) and the Luminex platform Bio-Plex 200 (Bio-Rad, Hemel Hempstead, UK) dual laser analyzer. Standard curves were generated using Bio-Plex Manager version 5.0. Lower limits of sensitivity for the Fluorokine Luminex were: $1.1 \mathrm{pg} / \mathrm{ml}$ for MMP-1, $7.3 \mathrm{pg} / \mathrm{ml}$ for MMP-3, $6.6 \mathrm{pg} / \mathrm{ml}$ for MMP-7, and $13.7 \mathrm{pg} / \mathrm{ml}$ for MMP-9. All samples were run with appropriate controls and were within the linear range of detection as indicated by the manufacturer.

\section{Western Blotting}

Cells were washed in PBS and scraped and homogenized in lysis buffer (62.5 mM Tris, 2\% SDS, 10\% glycerol, $50 \mathrm{mM}$ DDT with bromophenol blue) prior to storage at $-80^{\circ} \mathrm{C}$. Samples were denatured by heating to $90^{\circ} \mathrm{C}$ for $5 \mathrm{~min}$ and loaded on $4-12 \%$ NuPAGE Bis-Tris mini gels (Life Technologies) and run at $200 \mathrm{~V}$ for 70-90 $\mathrm{min}$. Proteins were transferred to a nitrocellulose membrane (GE Healthcare) at $4^{\circ} \mathrm{C}, 30 \mathrm{~V}$, for $1 \mathrm{~h}$ before blocking with 5\% skimmed milk protein/TBS/0.1\% Tween 20 buffer and incubating with diluted primary antibody. Membranes were incubated with diluted HRP-linked secondary antibody and developed using ECL Prime developing kit (GE Healthcare, Hatfield, UK).

\section{Transient Transfection with Promoter- Reporter Constructs}

MMP-1 promoter constructs expressed in the pGL3 firefly (Photinus pyralis) luciferase expression vector (Promega, Southampton, UK) were a gift of Professor Ian Clark (University of East Anglia, Norwich, UK). The full-length wild-type (WT) MMP-1 promoter construct (WT) comprised a 4,372 bp sequence upstream of the MMP-1 transcriptional start site. Deletion constructs ranged in size from 3,830 to $517 \mathrm{bp}$ (25). MMP-3 promoter constructs were designed in-house and cloned into the pGL3 vector. Truncations were generated using primers that incorporated restriction enzyme sites within the sequence of interest: MMP3-1R 5'-GCTTTACTTAGATCTATGTTGTCTC-3'; MMP3-4F 5'-GC TAGAGCTAGCAAGGATCCTGCAC-3'; MMP3-6R 5' -CTTCA TTTCCACAAGCTTTACTTAGCTCT-3'; MMP3-7F 5' -GTTTT CCTCCTCGAGAACCAGCAAATCC-3'; MMP3-8F 5' -CATCA TTCTACTGAGCTCTTACTCCCAAG-3'; MMP3-9F $5^{\prime}$-CCATG TCTGTAATCCTAGCACTTTGAG-3'; MMP3-10F 5'-GTTCAG TGTGGAAAATAGAGTAGCAGAGG-3'; MMP3-11-F 5'-GA TGGATTCTCGAGTTCAACTTCAAAGCATCTG-3'; MMP312-R 5'-GAGACAGAGATCTCACTATGTTGCCC-3'. PCR products of the $3 \mathrm{~kb} \mathrm{MMP}-3$ promoter region were digested in one step using NheI and BglII, followed by BamHI and BglII for cloning into pGL4 and pBSK vectors. Shorter fragments of the original $3 \mathrm{~kb}$ MMP-3 promoter region were digested using HindIII and XhoI for MMP3-7F/MMP3-6R; SacI and HindIII for MMP3-8F/MMP3-6R and MMP3-9F/MMP3-6R, and KpnI and HindIII for MMP3-10F/MMP3-6R. After $2 \mathrm{~h}$ incubation at $37^{\circ} \mathrm{C}$, enzymes were inactivated at $68^{\circ} \mathrm{C}$ for $20 \mathrm{~min}$. The constructs generated were $2,183,1,612$, and 642 bp in length. WT MMP-1/-3 promoters and respective truncations were inserted upstream of the luciferase reporter gene in the pGL3 vector. The PRL-TK plasmid constitutively expressing Renilla luciferase was used to control for transfection efficiency.

A549 cells were transfected when $60 \%$ confluent with FuGene 6 (Roche, Lewes, UK), and $0.8 \mu$ g plasmid DNA or control plasmid DNA. Sixteen hours after transfection, the cells were stimulated according to the experimental conditions. Twenty-four hours later, cells were washed once in PBS and lysed in passive lysis buffer (Promega). Luciferase assays were performed using the Promega Dual-Luciferase Reporter Assay kit (Promega) using an L-Max 2 luminometer (Molecular Devices, Sunnydale, CA, USA).

\section{Real-time PCR}

After $24 \mathrm{~h}$ incubation in the specified experimental settings, cells were lysed in TRI-reagent and total RNA extracted with the PureLink RNA mini kit (Life Technologies) with on-column DNase treatment. RNA concentrations and purity were evaluated using 
a Nanodrop spectrophotometer (Thermo Scientific, Wilmington, DE, USA). A total of $1 \mu \mathrm{g}$ of sample RNA was reverse transcribed using the Quantitect RT Kit (Qiagen, Crawley, UK) according to the manufacturer's instructions. Real-time PCR was performed using Brilliant II qPCR mastermix (Agilent, UK) on a Stratagene Mx3000p platform (Stratagene, La Jolla, USA). The thermal profile was $10 \mathrm{~min}$ at $95^{\circ} \mathrm{C}$, followed by $40-45$ cycles of $30 \mathrm{~s}$ at $95^{\circ} \mathrm{C}$ and $1 \mathrm{~min}$ at $60^{\circ} \mathrm{C}$. The cycle threshold $(\mathrm{Ct})$ at which amplification entered the exponential phase was determined for each well and analyte. $18 \mathrm{~S}$ ribosomal RNA, $\beta$-actin, and GAPDH RNA were used as reference genes. The following primers and probes were used to analyze target and reference genes.

MMP-1 forward primer 5'-AAGATGAAAGGTGGACCAAC AATT-3'; reverse primer 5'-CCAAGAGAATGGCCGAGTTC-3' and probe $5^{\prime}$-FAM CAGAGAGTACAACTTACATC GTGTTG CGGCTC-TAMRA-3'; GAPDH forward primer 5' $5^{\prime}$-CGCTTCG CTCTCTGCTCC T-3'; reverse primer 5' -CGACCAAATCCGT TGACTCC-3' and probe 5'-HEX-CGTCGCC AGCCGAGC CACAT-TAMRA-3' (both from Sigma-Aldrich); MMP-3 Hs00968305_m1;HDAC1Hs02621185_s1;HDAC2Hs00231032_ m1; HDAC3 Hs0018730_m1; HDAC4 Hs01041638_m1; HDAC5 Hs00608366_m1; HDAC8 Hs00218503_m1; 18S 4308329 and $\beta$-actin 431088E (all Taqman primer and probe mixes from Life Technologies). Cts from target genes were normalized to Cts for the reference genes that were measured simultaneously for each PCR assay performed.

\section{Transfection of Epithelial Cells with siRNA}

ON-TARGETplus SMARTpool siRNA oligonucleotides and transfection reagents were purchased from Dharmacon (Thermo Scientific). NHBEs were cultured in complete medium and transfected at $60-70 \%$ confluence. siRNA and Lipofectamine 2000 were diluted in Optimem and used at final concentrations of $30 \mathrm{nM}$ and $25 \mu \mathrm{g} / \mathrm{ml}$, respectively. After $4 \mathrm{~h}$, each well was washed with PBS and fresh BEGM was added. The cells were then rested overnight prior to stimulation with the experimental conditions. For analysis of mRNA expression, cells were lysed and total RNA was extracted $24 \mathrm{~h}$ after stimulation. For analysis of protein expression, cell culture supernatants were collected for ELISA and cells were washed in PBS and lysed in Western lysis buffer $48 \mathrm{~h}$ poststimulation.

\section{Chromatin Immunoprecipitation Assay (ChIP)}

Magna-ChIP kits and antibodies were purchased from Millipore (Watford, UK) and used according to manufacturer's instructions. The rabbit polyclonal anti-acetyl-Histone $\mathrm{H} 4$ antibody was raised against tetra acetylated $\mathrm{H} 4$ and recognizes intermediately acetylated $\mathrm{H} 4$, but not acetylation on lysine 16 . The rabbit polyclonal anti-acetyl-Histone 3 antibody was raised against acetylated $\mathrm{N}$-terminus of $\mathrm{H} 3$.

Cells were cultured in 100 or $150 \mathrm{~mm}$ tissue culture dishes until confluent then stimulated as previously described. Cells were fixed with fresh $1 \%$ paraformaldehyde solution for $10 \mathrm{~min}$ and the reaction was stopped with glycine. Chromatin was sheared by sonication with a Covaris S2 ultra-sonicator using an Adaptive Focused
Acoustics intensifier (KBioscience). Settings were as follows: temperature $6-8^{\circ} \mathrm{C}$, duty cycle $20 \%$, intensity 8,200 cycles/burst, 15 cycles of $30 \mathrm{~s}, 2 \times 10^{7}$ cell equivalents $/ \mathrm{ml}$. Immunoprecipitation was performed overnight at $4^{\circ} \mathrm{C}$ with $1 \times 10^{6}$ cell equivalents per condition. Purified DNA was eluted and PCR performed using SYBR Green JumpStart Taq Readymix. Reactions were performed in triplicate on the Stratagene Mx3000P platform (Stratagene, La Jolla, USA). The following custom unlabeled primers were designed in-house and supplied by Sigma. MMP-1 transcription start site forward primer 5'-TGGGATATTGGAGCAGC AAG-3' and reverse primer 5'-AGCTGTGCATACTGGCCT TT-3' (product size $82 \mathrm{bp}$ ); -500 bp MMP-1 promoter forward primer 5'-TAAGGGAAGCCAT GGTGCTA-3'; reverse primer 5'-AGGTTCCCTTCTGCCTTTGT-3' (product size 65 bp); $-2 \mathrm{kbp}$ MMP-1 promoter forward primer 5'TTGCCAGATG GGACAGTGTA-3' and reverse 5'-TCAGGAAAGCAGCAT GTGAC-3' (product size $123 \mathrm{bp}$ ); $-4 \mathrm{kbp}$ MMP-1 promoter forward primer 5'-CTTGAGGCCAGGAGTTTGAG-3' and reverse primer 5'-ACCACCAT GTCCCACTGATT-3' (product size 89 bp).

These assays were not performed in technical triplicates due to the number of cells required per condition.

\section{Statistics}

Unless otherwise stated, results shown are from experiments performed in triplicate and representative of at least two independent experiments. Comparisons between two groups were made using the Student's $t$-test (two-tailed with significance set as $p<0.05$ ). For comparison of three or more groups, one-way ANOVA was used with Tukey's correction for multiple comparisons. Unless otherwise stated in figure legends, graphs show mean values for triplicate samples and error bars are the SD.

\section{RESULTS}

\section{Class I HDACs Are Suppressed by Mtb Infection of Macrophages}

Experiments were designed to investigate epigenetic regulation of TB immunopathology, first investigating whether Mtb infection of macrophages altered Class I HDAC expression. Expression of Class I HDACs was repressed by Mtb infection, with a $68 \%$ decrease in HDAC1, 69\% in HDAC2, 76\% in HDAC3, and 58\% in HDAC8 compared with uninfected controls (all $p<0.05$ ) (Figures 1A-D). Next, we examined monocyte networkdependent stimulation of NHBEs by CoMTb. In contrast to macrophage stimulation by Mtb, CoMTb stimulation of NHBEs did not significantly alter accumulation of any class I HDAC mRNAs (Figures 1E-H). Expression of Class II HDACs 4 and 5 was also examined by RT-PCR. HDAC4 mRNA accumulation was increased by $48 \%$ in Mtb-infected macrophages, while no difference was observed for HDAC5 (Figures 1I,J). Increase in HDAC4 protein level was confirmed by western blot (Figure S1 in Supplementary Material). Class II HDAC expression in CoMTb-stimulated NHBEs was similar to control conditions (Figures 1K,L). Thus, exposure to live Mtb selectively suppressed macrophage class I HDAC expression. 

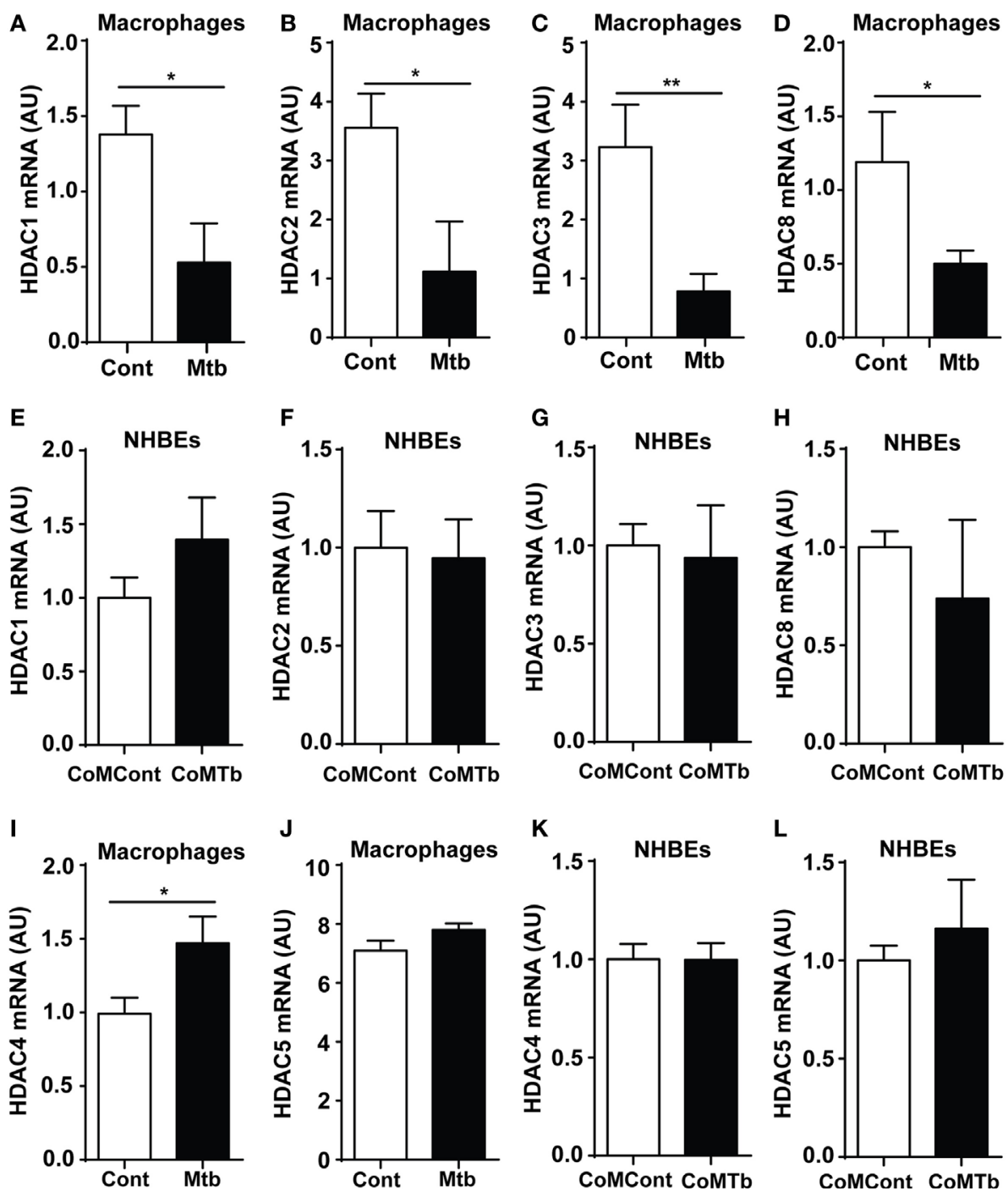

FIGURE 1 | Class I histone deacetylase (HDAC) expression is downregulated in Mycobacterium tuberculosis (Mtb)-infected macrophages Macrophages were infected with H37Rv at a multiplicity of infection of 1, while normal human bronchial epithelial cells (NHBEs) were stimulated with CoMTb (1:5 dilution), for $24 \mathrm{~h}$ before total RNA was extracted for Class I HDAC gene expression analysis. Figures show mRNA levels (AU) for: (A,E) HDAC1, (B,F) HDAC2, (C,G) HDAC3, (D,H) HDAC8 for macrophages and NHBEs, respectively. For Class II HDAC analysis, RNA was processed in a similar manner and figures show an $\mathbf{( I , K ) ~ H D A C 4 ~ m R N A ~ a n d ~} \mathbf{( J , L ) ~ H D A C 5 ~ m R N A ~ a c c u m u l a t i o n ~ f o r ~ m a c r o p h a g e s ~ a n d ~ N H B E s . ~ B a r s ~ r e p r e s e n t ~ m e a n ~} \pm$ SD and analysis was performed using Student's $t$-test. ${ }^{*} p<0.05 ;{ }^{* *} p<0.01$. AU, arbitrary units.

\section{Non-Selective HDAC Inhibition Reduces MMP-1 and -3 Expression in Macrophages and NHBEs during Mtb Infection}

Next, we investigated whether histone acetylation status affected MMP expression using the non-selective HDAC inhibitor (HDACi) TSA. A total of $100 \mathrm{ng} / \mathrm{ml}$ TSA markedly decreased Mtb-stimulated MMP-1 and MMP-3 secretion by macrophages (Figures 2A,B). In NHBEs, TSA significantly decreased baseline MMP-1 secretion by over 50\% ( $p<0.05$; Figure $2 \mathrm{C}$ ). CoMTbstimulated MMP-1 secretion was decreased by TSA treatment, although this did not reach statistical significance (Figure 2C). In contrast, CoMTb-stimulated MMP-3 secretion was significantly reduced in a dose-dependent manner by $25 \%$ with $1 \mathrm{ng} / \mathrm{ml}$ TSA (from 2.4 to $1.8 \mathrm{ng} / \mathrm{ml}$ ) and by $72 \%$ with $10 \mathrm{ng} / \mathrm{ml}$ TSA (685 pg/ml) (Figure 2D).

Further experiments were performed using an alternative chemical HDACi, CBHA (m-Carboxycinnamic Acid bisHydroxamide), to confirm that the observed effects were due to HDAC inhibition and not non-specific. Pretreatment of macrophages with $4 \mu \mathrm{M}$ CBHA before Mtb infection decreased MMP-1 secretion by $77 \%$ (from 8.89 to $2.05 \mathrm{ng} / \mathrm{ml}$ ) and MMP-3 secretion to undetectable levels (Figures 2E,F). CoMTb-driven MMP-1 secretion was reduced by CBHA treatment in a dosedependent manner. $5 \mu \mathrm{M}$ CBHA reduced MMP- 1 secretion by $41 \%$ (from 797 to $473 \mathrm{pg} / \mathrm{ml} ; p<0.05$; Figure 2G), while $1 \mu \mathrm{M}$ 


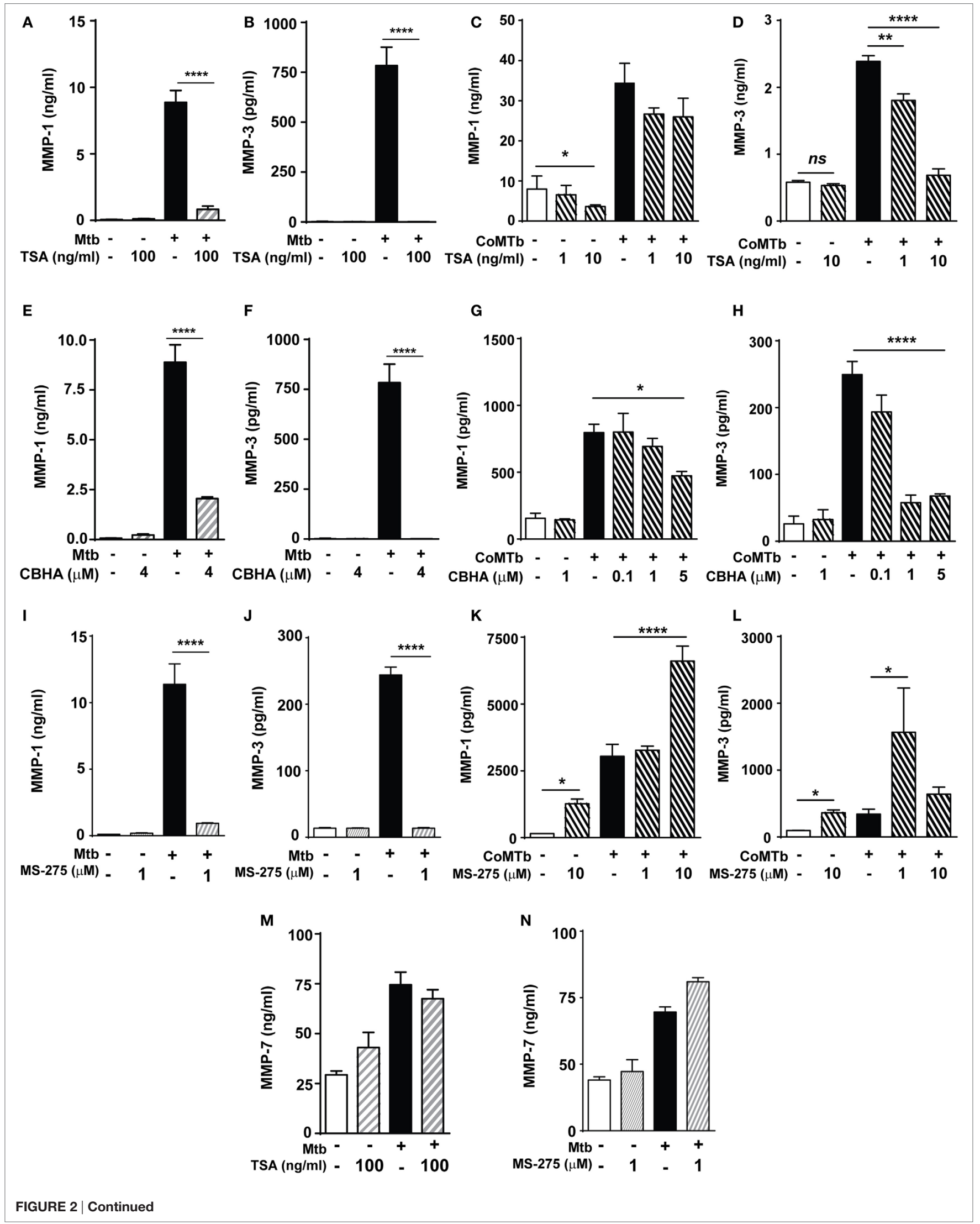


FIGURE 2 | Continued

Mycobacterium tuberculosis (Mtb)-driven matrix metalloproteinase (MMP)-1 and -3 secretion is suppressed by histone deacetylase (HDAC) inhibition. Macrophages and normal human bronchial epithelial cells (NHBEs) were preincubated with 1-100 ng/ml trichostatin A (TSA) (A-D), 0.1-5 $\mu$ M CBHA (E-H) or 1-10 $\mu \mathrm{M}$ MS-275 (I-L) to inhibit HDAC activity, prior to infection with H37Rv (multiplicity of infection 1) or stimulation with CoMTb (1:5 dilution) for 72 h, then MMP-1 and -3 secretion was measured. Pretreatment with TSA suppressed: (A) MMP-1 and (B) MMP-3 secretion from Mtb-infected macrophages. In CoMTb-stimulated NHBEs (C), MMP-1 secretion was unaltered and (D) MMP-3 secretion decreased with TSA treatment. Pretreatment with CBHA suppressed: (E) MMP-1 and (F) MMP-3 secretion from Mtb-infected macrophages and (G) MMP-1 and (H) MMP-3 secretion from CoMTb-stimulated NHBEs. The Class I selective HDACi MS-275 suppressed: (I) MMP-1 and (J) MMP-3 secretion from Mtb-infected macrophages, while it increased (K) MMP-1 secretion and decreased (L) MMP-3 secretion from CoMTb-stimulated NHBEs. Secretion of MMP-7 was not affected by (M) TSA and (N) 1 MM MS-275 treatment in Mtb-infected macrophages. Bars represent mean $\pm \mathrm{SD}$ and analysis was performed using one-way ANOVA with Tukey's posttest. ${ }^{\star} p<0.05$; ${ }^{\star \star} p<0.01 ;{ }^{\star \star \star \star} p<0.0001$. CBHA, m-Carboxycinnamic Acid bis-Hydroxamide.

CBHA was sufficient to completely inhibit CoMTb-induced MMP-3 secretion $(p<0.0001$; Figure $2 \mathbf{H})$. These results indicate that HDACs may differ between cell types, each with specific MMP regulatory pathways.

The HDAC class I-selective inhibitor MS-275 ( $1 \mu \mathrm{M})$ inhibited Mtb-driven macrophage MMP-1 secretion by $92 \%$ and reduced MMP-3 concentrations by $94.4 \%$ (Figures 2I,J). This supports the earlier finding and implies a key regulatory role for class I HDACs in macrophages MMP-1/-3 expression. In contrast, MS-275 enhanced MMP-1 secretion by both unstimulated $(p<0.05)$ and CoMTb-stimulated NHBEs ( $p<0.0001$; Figure 2K). MS-275 at a low concentration of $1 \mu \mathrm{M}$ increased MMP-3 secretion 4.6-fold compared to CoMTb alone $(p<0.05)$, but this was not observed at the higher concentration of $10 \mu \mathrm{M}$ MS-275 (Figure 2L), possibly due to sublethal cell toxicity, which could not be detected by cell viability experiments. The effects of these HDACi on MMP secretion were selective, since neither TSA nor $1 \mu \mathrm{M}$ MS-275 significantly altered MMP-7 secretion by Mtb-infected macrophages (Figures 2M,N).

\section{Silencing HDAC1 Expression Does Not Affect CoMTb-Driven MMP-1 Expression}

Next, we investigated whether a specific class I HDAC enzyme was necessary for CoMTb-induced MMP-1 and -3 expression. HDAC1 mRNA was reduced by more than $80 \%$ in CoMTbstimulated cells transfected with $30 \mathrm{nM}$ HDAC1 siRNA compared to non-targeting (NT) siRNA or untransfected controls (Figure 3A; $p=0.001$ ). Despite efficient HDAC1 silencing, no significant differences were observed in MMP-1 mRNA accumulation (Figure 3B). Consistent with this, MMP-1 concentrations were $3,204 \mathrm{pg} / \mathrm{ml}$ in CoMTb/HDAC1 siRNA treated samples compared to $3,746 \mathrm{pg} / \mathrm{ml}$ in the CoMTb/NT siRNA samples (Figure 3C). MMP-3 mRNA was upregulated threefold by CoMTb stimulation but no difference was observed between NT and HDAC1 siRNA-transfected NHBEs (Figure 3D). MMP-3 protein secretion in the NT-transfected cells was upregulated by CoMTb $(p<0.001)$, and MMP-3 secretion was reduced by $30 \%$ in HDAC1 siRNA-transfected cells compared to NT-transfected conditions ( $p<0.01$; Figure 3E). Silencing of HDAC2 in epithelial cells with siRNA (Figure 3F) was also effective and increased CoMTb-stimulated MMP-1, but not MMP-3, mRNA expression compared to CoMTb alone $(p<0.05$; Figures 3G,H). Silencing HDAC3 with siRNA did not affect MMP-1 or MMP-3 expression (Figures S2A-C in Supplementary Material).

\section{Macrophage-Derived MMP-1 and -3 Gene Expression and Secretion during Mtb Infection Are Blocked by HAT Inhibition}

Next, the role of HAT activity was investigated using the inhibitor HATi II. $10 \mu \mathrm{M}$ HATi II significantly decreased MMP-1 secretion from Mtb-infected macrophages by $56 \%$ (from 5,029 to $2,187 \mathrm{pg} / \mathrm{ml}$ ) and mRNA accumulation by $62 \%$ (Figures 4A,B). MMP-3 secretion was decreased from 1,653 to $190 \mathrm{pg} / \mathrm{ml}$ $(p<0.0001$, Figure 4C). There was a non-significant trend to decreased MMP-3 mRNA accumulation with HATi II treatment (Figure 4D). HATi II treatment did not affect MMP-7 secretion in response to Mtb infection (Figure S3 in Supplementary Material).

A second HAT inhibitor, AA $(10 \mu \mathrm{M})$, reduced Mtb-infected macrophage MMP-1 secretion by $74 \%$ (from 5,029 to 1,302 pg/ml; $p<0.0001$ ) (Figure 4E). Similarly, a significant decrease in MMP-1 secretion was also detected in stimulated NHBE cells pretreated with AA (Figure S4 in Supplementary Material). Secretion of MMP-3 in Mtb-infected macrophages was also inhibited by $10 \mu \mathrm{M}$ AA $(p<0.01$; Figure $4 F)$. The AA compound is closely related to salicylic acid and has been reported to have some antimicrobial activity, including against Mtb $(26,27)$. We therefore investigated whether these results might be secondary to an effect on Mtb growth, but this was not altered in broth cultures containing AA at concentrations between 2 and $25 \mu \mathrm{M}$ (Figure 4G). These experiments support the hypothesis that HAT activity is required for inducible expression of MMP-1 and MMP-3 in macrophages and NHBEs stimulated with Mtb.

\section{MMP-1 and MMP-3 Promoter-Reporter Analysis in TB}

Plasmid promoter-reporter constructs of the MMP-1 and MMP-3 promoter regions were transfected into A549 respiratory epithelial cells to investigate the effect of Mtb-stimulation on promoter activity. A schematic representation of the relevant region of the human MMP-1 promoter region is shown in Figure 5A. CoMTb treatment increased promoter activity of the WT construct by more than threefold compared to controls $(p=0.02$; Figure $5 \mathbf{B})$. CoMTb-mediated promoter activation was significantly enhanced by 98 and $71 \%$ in the 3,830 and 2,942 bp constructs, respectively, compared to CoMTb-stimulated WT $(p<0.01)$. Further truncation of the promoter resulted in loss of CoMTbdriven promoter activity. The MMP-3 promoter, examined using similar methodology, showed a progressive reduction in both basal and CoMTb-stimulated promoter activity with truncation 

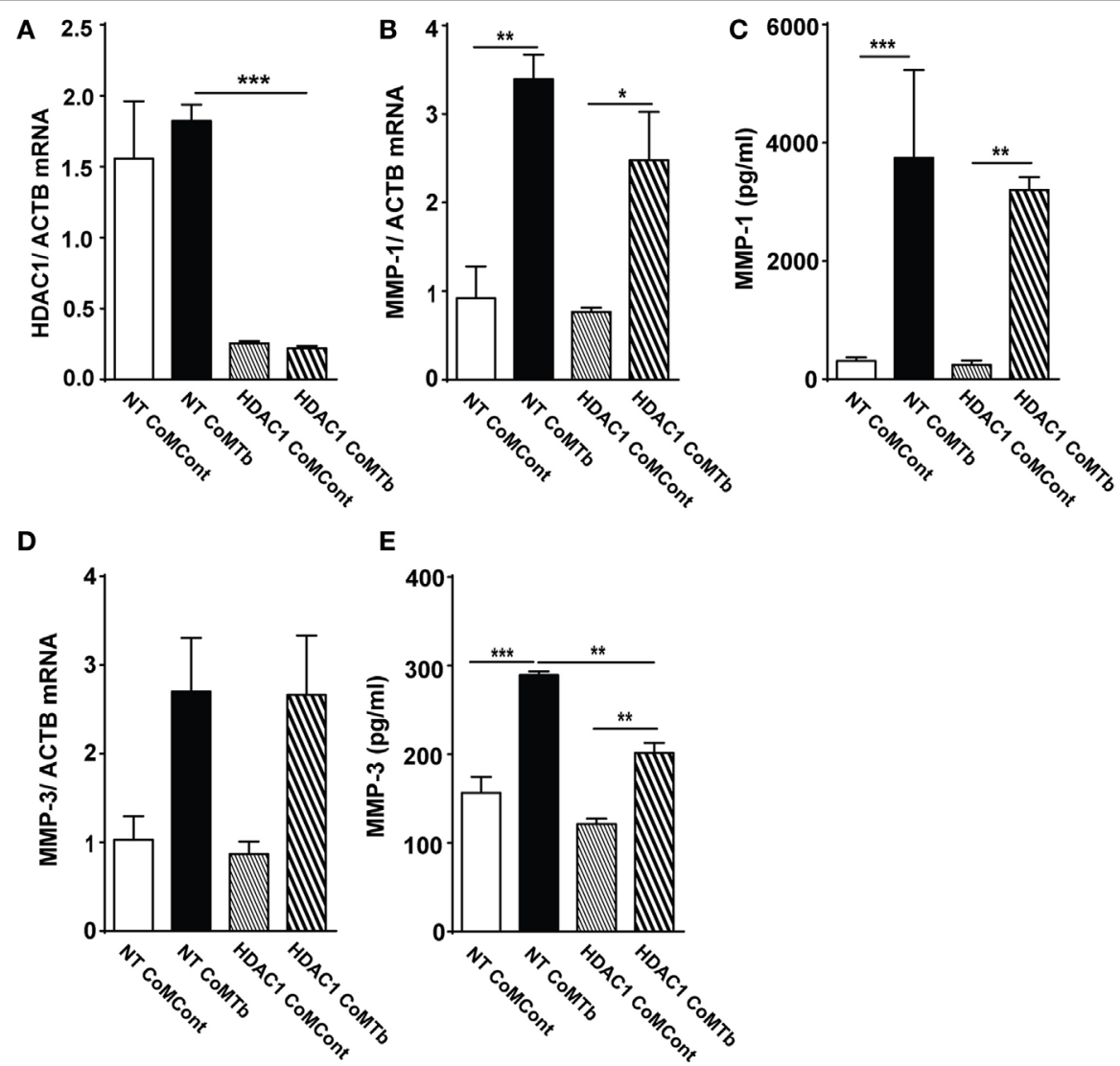

E
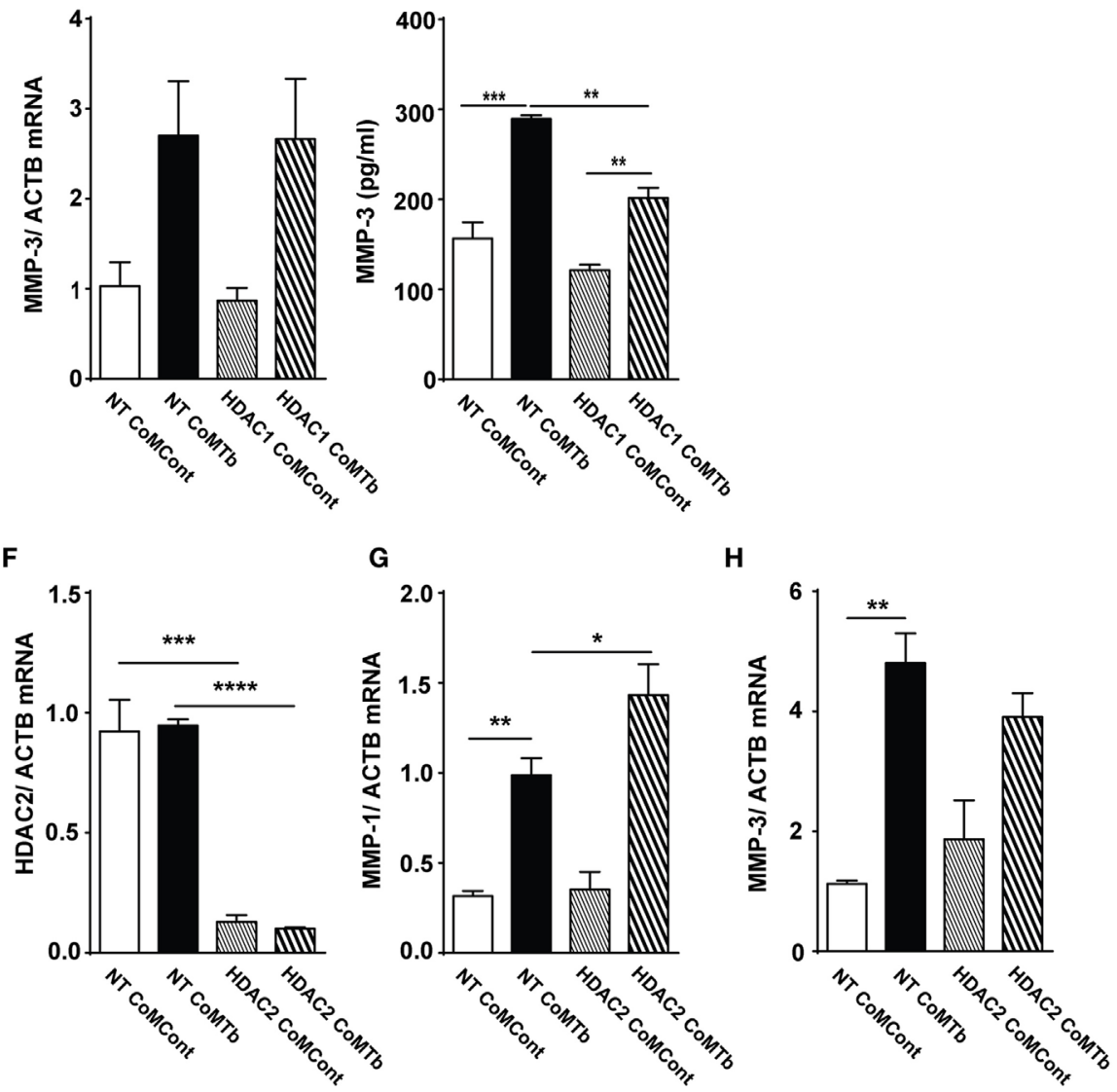

FIGURE 3 | Silencing of HDAC1 and HDAC2 expression does not inhibit CoMTb-driven matrix metalloproteinase (MMP)-1 gene expression. Normal human bronchial epithelial cells (NHBEs) were transfected with $30 \mathrm{nM}$ non-targeting (NT), HDAC1- or HDAC2-specific siRNA, or treated with transfection reagent alone. Cells were then stimulated with CoMTb (1:5) for 24 or 48 h. (A) HDAC1 mRNA normalized to the reference gene ACTB shows siRNA suppresses mRNA levels. (B) MMP-1 mRNA accumulation and (C) MMP-1 secretion following HDAC1 silencing are not significantly suppressed by siRNA. (D) MMP-3 mRNA accumulation remained unchanged, while (E) MMP-3 secretion decreased following HDAC1 silencing. (F) HDAC2 mRNA normalized to the reference gene ACTB and accumulation was silenced by HDAC2 siRNA. HDAC2 silencing increased MMP-1 mRNA accumulation (G) and did not affect MMP-3 mRNA accumulation (H) in CoMTb-stimulated NHBEs. mRNA of target genes was normalized to mRNA of the reference gene ACTB. Bars represent mean \pm SD and analysis was performed using one-way ANOVA with Tukey's posttest. ${ }^{*} p<0.05$; ${ }^{* \star} p<0.01$; ${ }^{* \star \star} p<0.0001$; ns, non-significant; ACTB, beta-actin; HDAC, histone deacetylase siRNA; NT, non-target siRNA.

of the construct from 1,612 to $642 \mathrm{bp}$ in length (Figure 5C) compared to WT. The 1,612 bp truncation is missing a stromelysin platelet-derived growth factor responsive element (SPRE; $-1,659$ to $-1,643 \mathrm{bp}$ ) and part of the stromelysin IL-1 responsive element $(-1,614$ to $-1,595 \mathrm{bp})$, and in addition, the $642 \mathrm{bp}$ truncation is missing 4 AP-1, 2 STAT3, and $1 \mathrm{c}$-rel binding sites. 

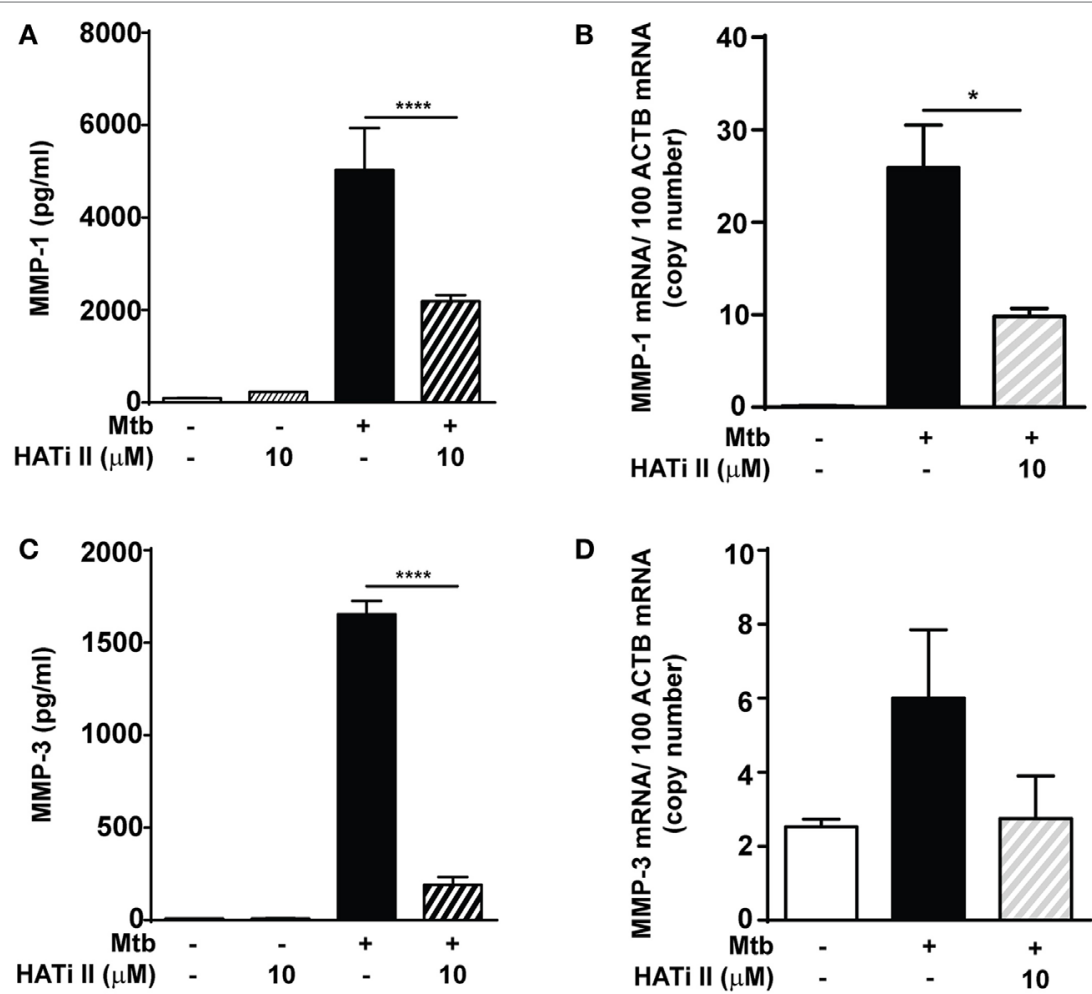

D
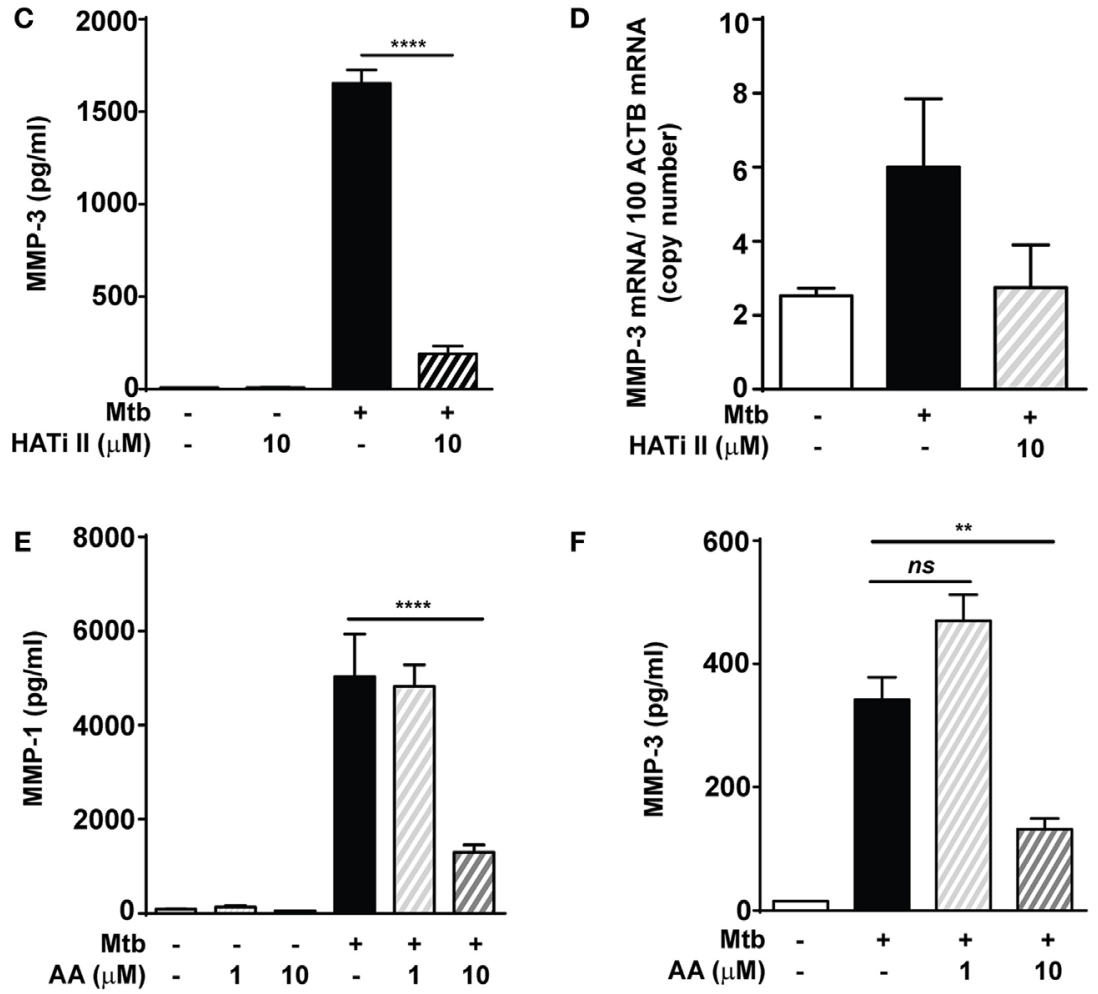

$\mathbf{F}$
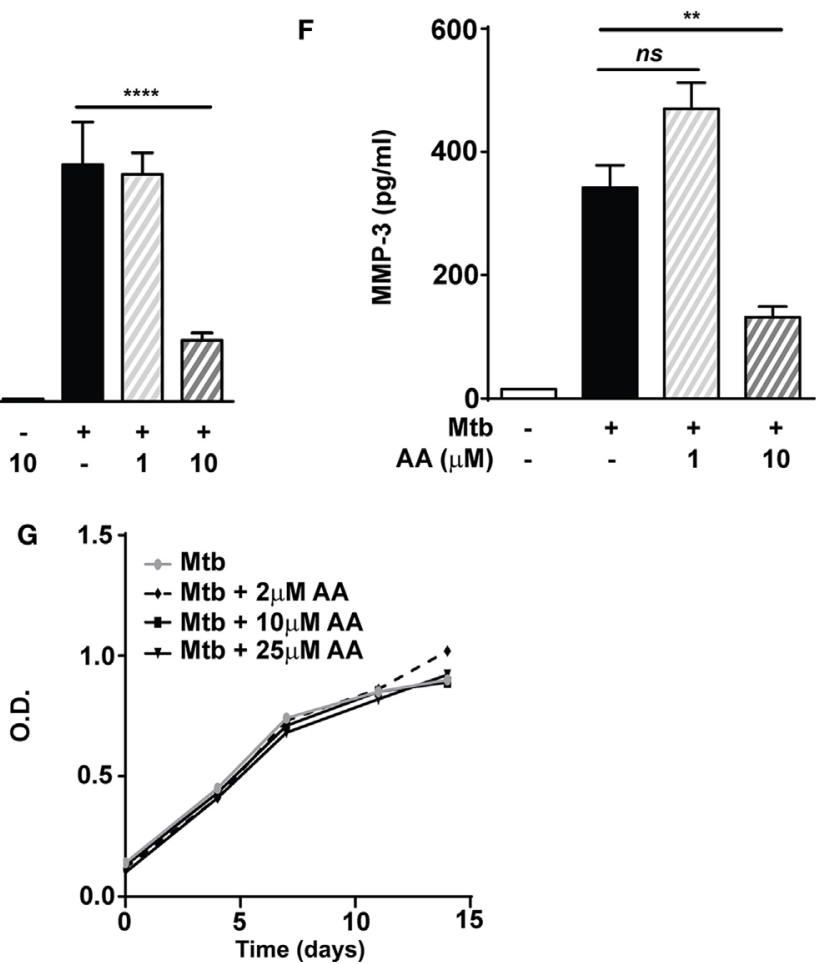

FIGURE 4 | HATi II inhibits Mycobacterium tuberculosis (Mtb)-driven matrix metalloproteinase (MMP)-1 and -3 secretion. Macrophages were preincubated with $10 \mu \mathrm{M} \mathrm{HATi}$ II or 1-10 $\mathrm{MM}$ AA prior to infection with H37Rv (multiplicity of infection 1). Total RNA was extracted after $24 \mathrm{~h}$ and cell culture supernatants were collected after $72 \mathrm{~h}$. Pre-treatment with the HATi ll suppressed: (A) MMP-1 secretion and (B) MMP-1 mRNA accumulation, as well as (C) MMP-3 secretion and (D) MMP-3 mRNA accumulation. Pre-treatment with 1-10 $\mu \mathrm{M}$ AA suppressed: (E) MMP-1 and (F) MMP-3 secreted concentrations in Mtb-infected macrophages. (G) H37Rv was cultured in the presence of AA 2-25 $\mu \mathrm{M}$ and bacterial growth was accessed by optical density (OD) measurements. Bars represent mean \pm SD and analysis was performed using one-way ANOVA with Tukey's posttest. ${ }^{\star} p<0.05$; ${ }^{\star \star} p<0.01$; ${ }^{\star \star \star \star} p<0.0001$; ns, non-significant; ACTB, beta-actin; AA, anacardic acid. 
A

Transcription start site

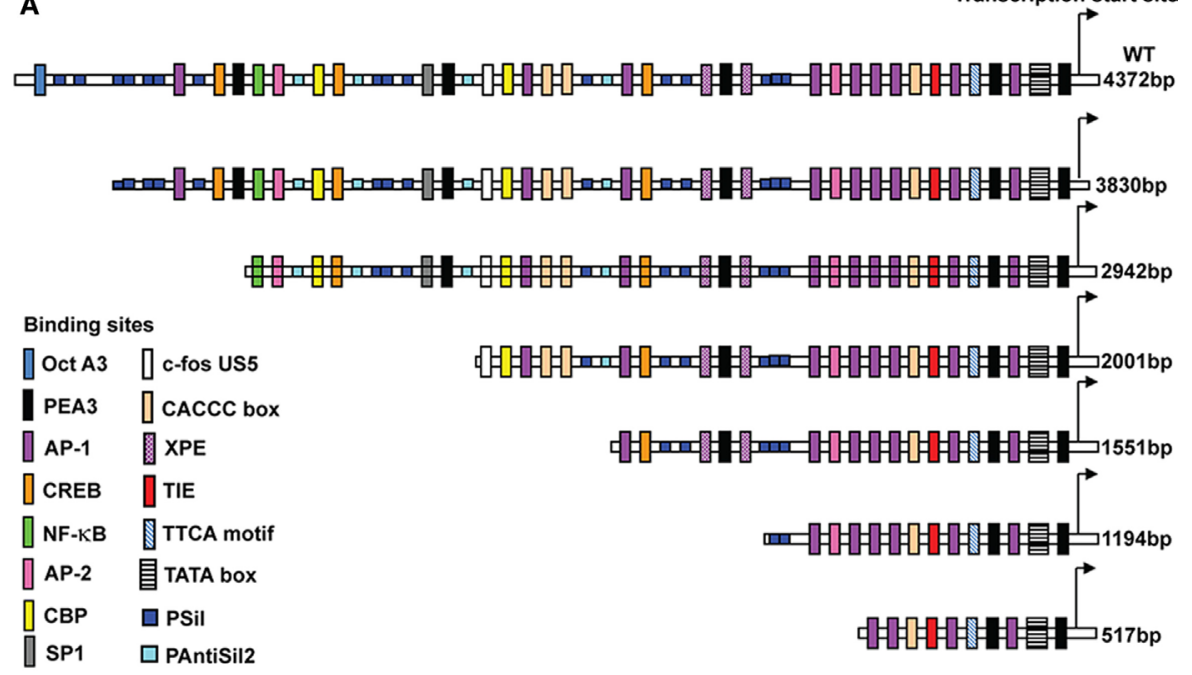

B CoMTb Promoter

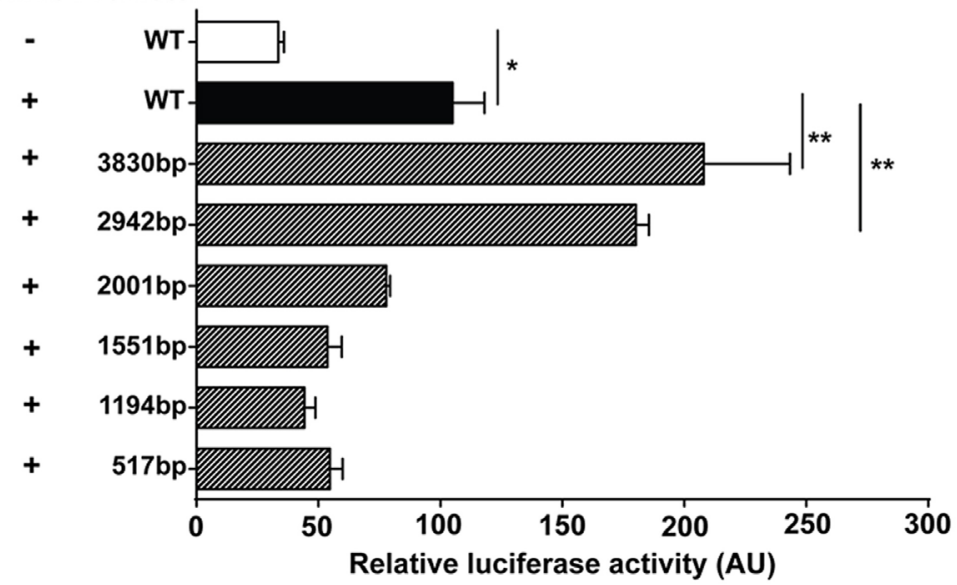

C

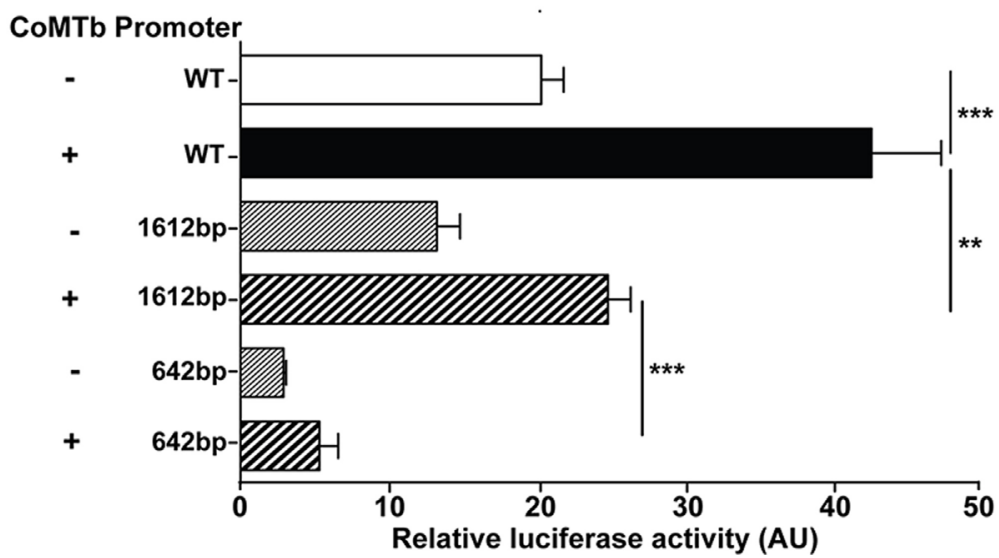

FIGURE 5 | Regulation of matrix metalloproteinase (MMP)-1 and -3 transcription in CoMTb-stimulated respiratory epithelial cells. WT and truncations of the MMP-1 and MMP-3 promoters expressed in the PGL3 firefly luciferase expression vectors were transfected into A549 cells. MMP-1 and -3 promoter activity for each truncation was assessed by relative luciferase activity compared to WT controls. (A) Schematic representation of WT MMP-1 promoter and truncations and relevant transcription factors binding sites. (B) MMP-1 promoter activity is significantly repressed in truncations upstream $-2,001$ bp of the transcriptional start site. (C) MMP-3 promoter activity is suppressed by truncations upstream $-1,612$ bp from the transcriptional start site. Bars represent mean \pm SD and analysis was performed using one-way ANOVA with Tukey's posttest. ${ }^{*} p<0.05 ;{ }^{* *} p<0.01 ;{ }^{* * *} p<0.001$. AU, arbitrary unit; WT, wild-type. 


\section{CoMTb-Driven MMP-1 Expression and Increased Histone Acetylation in the Promoter Region}

To further investigate whether epigenetic modifications of the MMP-1 promoter controlled the response to CoMTb, we examined the histone acetylation status of the MMP-1 promoter region by chromatin immunoprecipitation. Preliminary experiments using the respiratory epithelial A549 cell line suggested marked increases in histone $\mathrm{H} 4$ acetylation with CoMTb treatment at 1 and $2 \mathrm{~h}$ poststimulus (data not shown). In primary NHBEs, RNA Polymerase II binding to the MMP-1 promoter was increased between 10- and 15-fold in cells after $2 \mathrm{~h}$ of $\mathrm{CoMTb}$ treatment (Figure 6A). Histone H3 acetylation was increased $2 \mathrm{~h}$ poststimulation and was approximately threefold greater than under control conditions in the proximal promoter, and fivefold higher than control when measured $2 \mathrm{kbp}$ upstream of the MMP-1 transcriptional start site (Figure 6B). Detection of acetylated histone $\mathrm{H} 4$ after $2 \mathrm{~h}$ of $\mathrm{CoMTb}$ stimulation was also increased across the MMP-1 promoter region. Histone H4 acetylation was 10 -fold higher at $-2 \mathrm{kbp}$ and $-500 \mathrm{bp}$, and 6 -fold higher than unstimulated controls at the transcriptional start site (Figure 6C).

\section{DISCUSSION}

Upregulation of MMP-1 in TB is a critical event for the development of cavitation (9). Previous studies from our group and other have demonstrated that Mtb-stimulation upregulates MMP-1 expression, which is enzymatically active and able to degrade type I collagen, the main component of the lung's $\operatorname{ECM}[\mathrm{Al}(10,28,29)]$. Expression of other MMPs is also induced in pulmonary TB $(28,30)$, and MMPs are implicated in central nervous system immunopathology $(31,32)$. In this study, we demonstrated that expression of MMP-1 and -3 in response to Mtb is controlled by epigenetic changes in histone acetylation. HDACs are canonically considered to be negative regulators of gene expression, and we showed a change in the profile of HDAC expression following Mtb infection of macrophages. Downregulation of Class I HDAC gene expression was observed with a concomitant and selective upregulation of HDAC4 but not HDAC5. In contrast, in respiratory epithelial cells, Class I and Class II HDAC expression were unchanged after CoMTb stimulation, implying that this is a cell type-specific effect. TLR signaling is known to induce changes in HDAC expression and activity (33), and our findings are consistent with published evidence of selective changes in macrophage HDAC expression in response to specific inflammatory stimuli (34). Our data show that Mtb infection of macrophages induces a change in the cellular HDAC profile. We went on to investigate the likely effects of this change by performing experiments in which MMP responses were examined under conditions of both general and specific HDAC blockade.

Non-selective HDAC inhibition using TSA and the bipolar hybrid CBHA suppressed Mtb-driven MMP-1 and -3 secretion and mRNA accumulation in primary epithelial cells and macrophages. Such a paradoxical effect on MMP expression has been previously reported in an in vitro model of arthritis, where
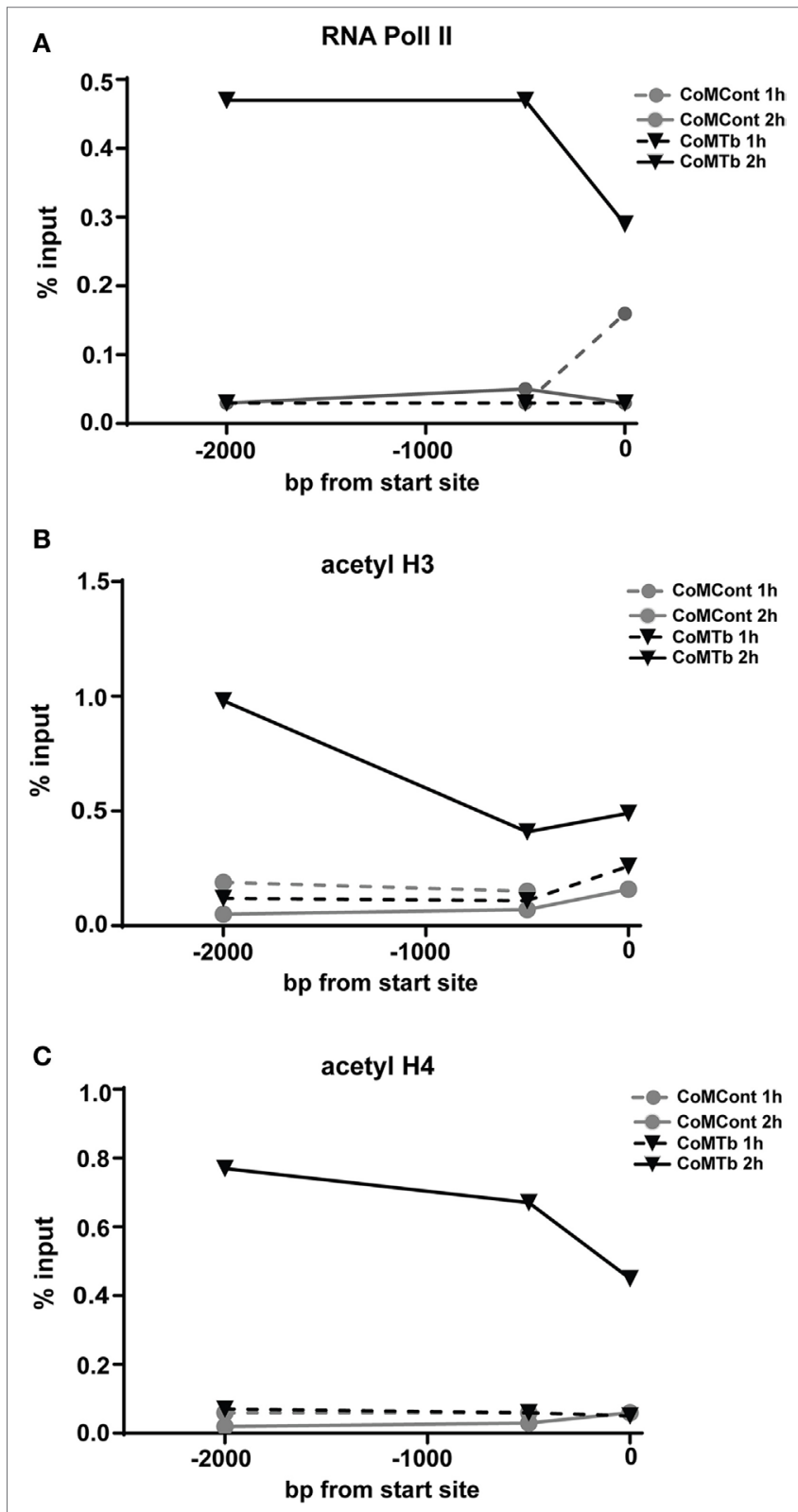

FIGURE 6 | Mycobacterium tuberculosis (Mtb)-driven matrix metalloproteinase (MMP)-1 expression is associated with increased RNA Pol II binding and increased histone $\mathrm{H3}$ and $\mathrm{H} 4$ acetylation of the MMP-1 promoter. ChIP assays were performed on normal human bronchial epithelial cells treated with CoMTb (black triangles) or control medium (gray circles) for $1 \mathrm{~h}$ (dashed line) or $2 \mathrm{~h}$ (solid line) poststimulation. (A) RNA Pol II, (B) acetylated histone $\mathrm{H} 3$, and $\mathbf{( C )}$ acetylated histone $\mathrm{H} 4$ association with the MMP-1 promoter increases after $2 \mathrm{~h}$ CoMTb stimulation, particularly between $-2,000$ to $-1,000 \mathrm{bp}$ from the transcriptional start site. Data presented as percentage of the total chromatin input (\% input) and figures are representative of three independent experiments. Acetyl $\mathrm{H} 3$, acetylated histone H3; Acetyl H4, acetylated histone H4; ChIP, chromatin immunoprecipitation; RNA Pol II, RNA polymerase II.

chondrocyte collagenase activity was inhibited by TSA (35). In a mouse model of arthritis, TSA also inhibited MMP-1, -3, and -13 expression (36). Similarly, LPS-induced MMP expression 
by murine bone marrow-derived macrophages was inhibited by TSA (37). The Class I selective HDACi MS-275 had contrasting effects: increasing basal and CoMTb-stimulated MMP-1 and -3 secretion in epithelial cells, while in Mtb-infected macrophages, it decreased MMP-1/-3 secretion. Similar inhibition of cytokine-induced MMP-1 was seen in MS-275 treated human chondrocytes (38). The effects of MS-275 may be due to selective inhibition of HDAC1 at lower concentrations, and additional effects on the activity of HDAC2 and 3 at higher concentrations (39). Individual HDAC enzymes are likely to play different roles in regulation of MMP expression, and since these chemicals affect function of multiple HDACs, it is impossible to dissect the relative contribution of each HDAC by a chemical inhibition approach alone.

The increased secretion of MMP-1 and -3 from NHBEs observed with Class I HDAC inhibition, as compared to nonselective HDAC inhibition, is consistent with the premise that Class I HDACs are key negative regulators of MMP expression. HDAC1 was shown to be recruited to the MMP-9 promoter site, reducing histone $\mathrm{H} 3$ acetylation and NF- $\kappa \mathrm{B}$ recruitment, leading to repression of MMP-9 expression in fibrosarcoma cells (40).

The enhancement of CoMTb-stimulated MMP expression observed with MS-275 led us to hypothesize that silencing the expression of HDAC1 might similarly increase inducible MMP expression. The catalytic activity of HDAC 1 and 2 is reliant on their incorporation as heterodimers into multiprotein assemblies (41) and therefore we expected that silencing either HDAC 1 or HDAC 2 would affect MMP expression. However, in spite of a high efficiency of HDAC1 silencing, MMP-1 expression was unaffected, and MMP-3 secretion was decreased in HDAC1-silenced cells. In contrast, upregulation of MMP-1 in CoMTb-stimulated conditions was further enhanced with HDAC2 inhibition, suggesting that MS-275 could be having its effect via inhibition of HDAC2 rather than HDAC1. The differing results for HDAC1 and HDAC2 silencing are unexpected given the close homology between these proteins, and consequently further dissection of their relative contributions to control of MMP expression is needed. In other experimental systems, different HDACs have been implicated in MMP regulation and there may be cell and stimulus specificity in host responses. In synovial fibroblasts from arthritis patients, HDAC1 siRNA enhanced TNF $\alpha$-induced MMP-1 expression (42), whereas HDAC4 was identified as a negative regulator of MMP-1 expression (43).

Consistent with the hypothesis that epigenetic modifications regulate MMP secretion in TB, expression of MMP-1 and - 3 were both suppressed by HAT inhibition with HATi II. Experiments using a structurally unrelated HAT inhibitor, AA, generated consistent data. Similarly, in human dermal fibroblasts exposed to UV light, AA inhibited MMP-1 expression, as did siRNA silencing of p300 expression. Increased HAT activity and histone $\mathrm{H} 3$ acetylation and decreased HDAC activity preceded changes in MMP-1 gene expression (44). The finding that both HAT and HDAC inhibition decreased MMP-1 and - 3 expression, while apparently contradictory, may reflect the complex interdependence of these processes. It is well recognized that many non-histone substrates of these enzymes exist $(45,46)$ and indeed phylogenetic studies have indicated that bacterial HDAC homologs pre-date the existence of histones (47). Lysine acetylation of many non-histone proteins has been shown to be enhanced by HDAC inhibition, for example, with MS-275 (46).

Many transcription factors contain such lysine acetylation sites, including cAMP response element-binding protein (CREB), whose activity is increased in the presence of TSA (48). CREB can be acetylated at three sites, enhancing its transcription factor activity, and HDAC8 is known to act on the CREB acetylation sites (49). The NF- $\kappa B$ family of transcription factors is also subject to posttranslational modification including acetylation as well as phosphorylation (50). Myocyte enhancer factor-2 is deacetylated by HDAC3, which also acts on the HATs PCAF and p300/CBP (51). In addition to transcription factors and HATs, the HDACs themselves contain lysine acetylation sites, as do a number of structural and regulatory proteins (52). Therefore, it is difficult to dissect out the relative contribution of inhibition of histone acetylation/deacetylation compared to effects on these other substrates when considering the effects of chemical inhibitors, and our findings indicate a complex interplay of signaling pathways occurs during infection.

The promoter-reporter analysis showed that inhibitory elements located 4,372-2,942 bp upstream from the MMP-1 transcriptional start site decrease promoter activation, since deletion of this region enhanced CoMTb-driven promoter activity. The area between $-2,942$ and $-2,001$ bp contains several critical elements required for the induction of gene expression, including a putative NF- $\mathrm{\kappa B}$ binding site. There is also an AP-1 site at $-1,950$ bp just proximal to the $-2,001$ bp truncation that might be functionally disrupted by this truncation. There is substantial evidence that MMP-1 expression is regulated by both NF- $\mathrm{BB}$ and AP-1 family transcription factors $(8,53,54)$, and our data support a central role. Similarly, multiple transcription binding sites may be important in MMP-3 promoter function. Our chromatin immunoprecipitation studies demonstrated that $\mathrm{CoMTb}$ stimulation leads to increased $\mathrm{H} 3$ and $\mathrm{H} 4$ acetylation at the MMP-1 promoter region. Histone acetylation was an early event after CoMTb stimulation occurring concurrently with binding of RNA Pol II to the MMP-1 promoter.

In summary, MMP- 1 and 3 expression in $\mathrm{TB}$ is regulated by HDAC and HAT activity. MMP-1 upregulation, as a result of epigenetic control, has the potential to drive tissue damage in the lung, thereby facilitating spread of infection and development of pathology. Chemical inhibition suggests that HDAC and HAT activity is necessary for inducible expression of MMP-1 and -3 in Mtb-infected macrophages, but that different mechanisms operate in NHBEs, where class I HDACs appear to act as a brake on collagenase expression. This is a selective effect, as MMP-7, which is constitutively expressed in MDMs and upregulated by Mtb infection, was unaffected by HDAC and HAT inhibition.

The minimal inhibition of MMP responses seen with siRNA targeting individual class I HDACs implies that there may be some redundancy of function. Increased histone acetylation in the MMP-1 promoter region follows Mtb stimulation, favoring RNA Pol II binding, and results in upregulation of MMP gene 
transcription and enzyme secretion. Tissue breakdown mediated by MMP activity is a key event in TB immunopathology and manipulation of host epigenetic changes have potential applications as host-directed therapy in the era of rising drug resistance in TB.

\section{AUTHOR CONTRIBUTIONS}

JF conceived the project. RM, PE, and JF designed the experiments and analyzed the data. RM, SB, and FS performed the experiments and generated the data. SB, RM, PE, and JF wrote the manuscript, which was reviewed and final version approved by all authors.

\section{REFERENCES}

1. WHO. Global Tuberculosis Report 2016. Geneva: World Health Organization (2016).

2. Wallis RS, Hafner R. Advancing host-directed therapy for tuberculosis. Nat Rev Immunol (2015) 15(4):255-63. doi:10.1038/nri3813

3. Thuong NT, Dunstan SJ, Chau TT, Thorsson V, Simmons CP, Quyen NT, et al. Identification of tuberculosis susceptibility genes with human macrophage gene expression profiles. PLoS Pathog (2008) 4(12):e1000229. doi:10.1371/ journal.ppat.1000229

4. Azad AK, Sadee W, Schlesinger LS. Innate immune gene polymorphisms in tuberculosis. Infect Immun (2012) 80(10):3343-59. doi:10.1128/IAI. 00443-12

5. McGarry Houghton A. Matrix metalloproteinases in destructive lung disease. Matrix Biol (2015) 44-46:167-74. doi:10.1016/j.matbio.2015.02.002

6. Dobaczewski M, Gonzalez-Quesada C, Frangogiannis NG. The extracellular matrix as a modulator of the inflammatory and reparative response following myocardial infarction. J Mol Cell Cardiol (2010) 48(3):504-11. doi:10.1016/j. yjmcc.2009.07.015

7. Ong CW, Elkington PT, Friedland JS. Tuberculosis, pulmonary cavitation, and matrix metalloproteinases. Am J Respir Crit Care Med (2014) 190(1):9-18. doi:10.1164/rccm.201311-2106PP

8. Green JA, Elkington PT, Pennington CJ, Roncaroli F, Dholakia S, Moores RC, et al. Mycobacterium tuberculosis upregulates microglial matrix metalloproteinase- 1 and -3 expression and secretion via NF-kappaB and activator protein-1-dependent monocyte networks. J Immunol (2010) 184(11): 6492-503. doi:10.4049/jimmunol.0903811

9. Elkington P, Shiomi T, Breen R, Nuttall RK, Ugarte-Gil CA, Walker NF, et al. MMP-1 drives immunopathology in human tuberculosis and transgenic mice. J Clin Invest (2011) 121(5):1827-33. doi:10.1172/JCI45666

10. Shammari Al, Shiomi BT, Tezera L, Bielecka MK, Workman V, Sathyamoorthy T, et al. The extracellular matrix regulates granuloma necrosis in tuberculosis. J Infect Dis (2015) 212(3):463-73. doi:10.1093/infdis/jiv076

11. Singh S, Saraiva L, Elkington PT, Friedland JS. Regulation of matrix metalloproteinase-1, -3, and -9 in Mycobacterium tuberculosis-dependent respiratory networks by the rapamycin-sensitive PI3K/p70(S6K) cascade. FASEB J (2014) 28(1):85-93. doi:10.1096/f.13-235507

12. Chernov AV, Strongin AY. Epigenetic regulation of matrix metalloproteinases and their collagen substrates in cancer. Biomol Concepts (2011) 2(3):135-47. doi:10.1515/bmc.2011.017

13. Loffek S, Schilling O, Franzke CW. Series "matrix metalloproteinases in lung health and disease": biological role of matrix metalloproteinases: a critical balance. Eur Respir J (2011) 38(1):191-208. doi:10.1183/09031936. 00146510

14. Mortaz E, Masjedi MR, Barnes PJ, Adcock IM. Epigenetics and chromatin remodeling play a role in lung disease. Tanaffos (2011) 10(4):7-16.

15. Bird A. Perceptions of epigenetics. Nature (2007) 447(7143):396-8. doi:10.1038/nature05913

16. Goldberg AD, Allis CD, Bernstein E. Epigenetics: a landscape takes shape. Cell (2007) 128(4):635-8. doi:10.1016/j.cell.2007.02.006

17. Bannister AJ, Kouzarides T. Regulation of chromatin by histone modifications. Cell Res (2011) 21(3):381-95. doi:10.1038/cr.2011.22

\section{FUNDING}

RM was a Wellcome Trust Clinical Research Fellow. SB was supported by the Portuguese Foundation for Science and Technology (FCT). SB and JF were supported by the Rosetrees Trust and Breathing Matters charities. JF acknowledges support of the Biomedical Research Centre at Imperial College.

\section{SUPPLEMENTARY MATERIAL}

The Supplementary Material for this article can be found online at http://journal.frontiersin.org/article/10.3389/fimmu.2017.00602/ full\#supplementary-material.

18. de Ruijter AJ, van Gennip AH, Caron HN, Kemp S, van Kuilenburg AB. Histone deacetylases (HDACs): characterization of the classical HDAC family Biochem J (2003) 370(Pt 3):737-49. doi:10.1042/bj20021321

19. Shahbazian MD, Grunstein M. Functions of site-specific histone acetylation and deacetylation. Annu Rev Biochem (2007) 76:75-100. doi:10.1146/annurev. biochem.76.052705.162114

20. Lee KH, Choi EY, Kim MK, Kim KO, Jang BI, Kim SW, et al. Inhibition of histone deacetylase activity down-regulates urokinase plasminogen activator and matrix metalloproteinase- 9 expression in gastric cancer. Mol Cell Biochem (2010) 343(1-2):163-71. doi:10.1007/s11010-010-0510-x

21. Kleinsteuber K, Heesch K, Schattling S, Kohns M, Sander-Julch C, Walzl G, et al. Decreased expression of miR-21, miR-26a, miR-29a, and miR-142-3p in CD4(+) T cells and peripheral blood from tuberculosis patients. PLoS One (2013) 8(4):e61609. doi:10.1371/journal.pone.0061609

22. McErlean P, Favoreto S Jr, Costa FF, Shen J, Quraishi J, Biyasheva A, et al. Human rhinovirus infection causes different DNA methylation changes in nasal epithelial cells from healthy and asthmatic subjects. BMC Med Genomics (2014) 7:37. doi:10.1186/1755-8794-7-37

23. Jaspers I, Horvath KM, Zhang W, Brighton LE, Carson JL, Noah TL. Reduced expression of IRF7 in nasal epithelial cells from smokers after infection with influenza. Am J Respir Cell Mol Biol (2010) 43(3):368-75. doi:10.1165/ rcmb.2009-0254OC

24. Feng Q, Su Z, Song S, Chiu H, Zhang B, Yi L, et al. Histone deacetylase inhibitors suppress RSV infection and alleviate virus-induced airway inflammation. Int J Mol Med (2016) 38(3):812-22. doi:10.3892/ ijmm.2016.2691

25. Wang P, Guan PP, Wang T, Yu X, Guo JJ, Konstantopoulos K, et al. Interleukin1beta and cyclic AMP mediate the invasion of sheared chondrosarcoma cells via a matrix metalloproteinase-1-dependent mechanism. Biochim Biophys Acta (2014) 1843(5):923-33. doi:10.1016/j.bbamcr.2014.01.018

26. Swamy BN, Suma TK, Rao GV, Reddy GC. Synthesis of isonicotinoylhydrazones from anacardic acid and their in vitro activity against Mycobacterium smegmatis. Eur J Med Chem (2007) 42(3):420-4. doi:10.1016/j.ejmech.2006.09.009

27. Omanakuttan A, Nambiar J, Harris RM, Bose C, Pandurangan N, Varghese RK, et al. Anacardic acid inhibits the catalytic activity of matrix metalloproteinase-2 and matrix metalloproteinase-9. Mol Pharmacol (2012) 82(4):614-22. doi:10.1124/mol.112.079020

28. Brilha S, Sathyamoorthy T, Stuttaford LH, Walker NF, Wilkinson RJ, Singh S, et al. Early secretory antigenic target- 6 drives matrix metalloproteinase-10 gene expression and secretion in tuberculosis. Am J Respir Cell Mol Biol (2017) 56(2):223-32. doi:10.1165/rcmb.2016-0162OC

29. Tezera LB, Bielecka MK, Chancellor A, Reichmann MT, Shammari BA, Brace P, et al. Dissection of the host-pathogen interaction in human tuberculosis using a bioengineered 3-dimensional model. Elife (2017) 6:e21283. doi:10.7554/eLife.21283

30. Kubler A, Luna B, Larsson C, Ammerman NC, Andrade BB, Orandle M, et al. Mycobacterium tuberculosis dysregulates MMP/TIMP balance to drive rapid cavitation and unrestrained bacterial proliferation. J Pathol (2015) 235(3):431-44. doi:10.1002/path.4432

31. Majeed S, Singh P, Sharma N, Sharma S. Role of matrix metalloproteinase-9 in progression of tuberculous meningitis: a pilot study in patients at 
different stages of the disease. BMC Infect Dis (2016) 16(1):722. doi:10.1186/ s12879-016-1953-9

32. Ong CW, Pabisiak PJ, Brilha S, Singh P, Roncaroli F, Elkington PT, et al. Complex regulation of neutrophil-derived MMP-9 secretion in central nervous system tuberculosis. J Neuroinflammation (2017) 14(1):31. doi:10.1186/ s12974-017-0801-1

33. Aung HT, Schroder K, Himes SR, Brion K, van Zuylen W, Trieu A, et al. LPS regulates proinflammatory gene expression in macrophages by altering histone deacetylase expression. FASEB J (2006) 20(9):1315-27. doi:10.1096/ f. $05-5360 \mathrm{com}$

34. Bell RD, Winkler EA, Singh I, Sagare AP, Deane R, Wu Z, et al. Apolipoprotein E controls cerebrovascular integrity via cyclophilin A. Nature (2012) 485(7399):512-6. doi:10.1038/nature11087

35. Wang X, Song Y, Jacobi JL, Tuan RS. Inhibition of histone deacetylases antagonized FGF2 and IL-1beta effects on MMP expression in human articular chondrocytes. Growth Factors (2009) 27(1):40-9. doi:10.1080/ 08977190802625179

36. Nasu Y, Nishida K, Miyazawa S, Komiyama T, Kadota Y, Abe N, et al. Trichostatin $\mathrm{A}$, a histone deacetylase inhibitor, suppresses synovial inflammation and subsequent cartilage destruction in a collagen antibody-induced arthritis mouse model. Osteoarthritis Cartilage (2008) 16(6):723-32. doi:10.1016/ j.joca.2007.10.014

37. Roger T, Lugrin J, Le Roy D, Goy G, Mombelli M, Koessler T, et al. Histone deacetylase inhibitors impair innate immune responses to toll-like receptor agonists and to infection. Blood (2010) 117(4):1205-17. doi:10.1182/ blood-2010-05-284711

38. Culley KL, Hui W, Barter MJ, Davidson RK, Swingler TE, Destrument AP, et al. Class I histone deacetylase inhibition modulates metalloproteinase expression and blocks cytokine-induced cartilage degradation. Arthritis Rheum (2013) 65(7):1822-30. doi:10.1002/art.37965

39. Khan N, Jeffers M, Kumar S, Hackett C, Boldog F, Khramtsov N, et al. Determination of the class and isoform selectivity of small-molecule histone deacetylase inhibitors. Biochem J (2008) 409(2):581-9. doi:10.1042/ BJ20070779

40. Mittelstadt ML, Patel RC. AP-1 mediated transcriptional repression of matrix metalloproteinase- 9 by recruitment of histone deacetylase 1 in response to interferon beta. PLoS One (2012) 7(8):e42152. doi:10.1371/journal. pone. 0042152

41. Alland L, David G, Shen-Li H, Potes J, Muhle R, Lee HC, et al. Identification of mammalian Sds3 as an integral component of the Sin3/histone deacetylase corepressor complex. Mol Cell Biol (2002) 22(8):2743-50. doi:10.1128/ MCB.22.8.2743-2750.2002

42. Horiuchi M, Morinobu A, Chin T, Sakai Y, Kurosaka M, Kumagai S. Expression and function of histone deacetylases in rheumatoid arthritis synovial fibroblasts. J Rheumatol (2009) 36(8):1580-9. doi:10.3899/jrheum. 081115

43. Maciejewska-Rodrigues $\mathrm{H}$, Karouzakis E, Strietholt S, Hemmatazad H, Neidhart M, Ospelt C, et al. Epigenetics and rheumatoid arthritis: the role of SENP1 in the regulation of MMP-1 expression. JAutoimmun (2009) 35(1):15-22. doi:10.1016/j.jaut.2009.12.010
44. Kim DH, Lipke EA, Kim P, Cheong R, Thompson S, Delannoy M, et al. Nanoscale cues regulate the structure and function of macroscopic cardiac tissue constructs. Proc Natl Acad Sci U S A (2010) 107(2):565-70. doi:10.1073/ pnas. 0906504107

45. Wolffe AP. Histone deacetylase: a regulator of transcription. Science (1996) 272(5260):371-2. doi:10.1126/science.272.5260.371

46. Choudhary C, Kumar C, Gnad F, Nielsen ML, Rehman M, Walther TC, et al. Lysine acetylation targets protein complexes and co-regulates major cellular functions. Science (2009) 325(5942):834-40. doi:10.1126/science. 1175371

47. Gregoretti IV, Lee YM, Goodson HV. Molecular evolution of the histone deacetylase family: functional implications of phylogenetic analysis. J Mol Biol (2004) 338(1):17-31. doi:10.1016/j.jmb.2004.02.006

48. Michael LF, Asahara H, Shulman AI, Kraus WL, Montminy M. The phosphorylation status of a cyclic AMP-responsive activator is modulated via a chromatin-dependent mechanism. Mol Cell Biol (2000) 20(5):1596-603. doi:10.1128/MCB.20.5.1596-1603.2000

49. Lu Q, Hutchins AE, Doyle CM, Lundblad JR, Kwok RP. Acetylation of cAMP-responsive element-binding protein (CREB) by CREB-binding protein enhances CREB-dependent transcription. J Biol Chem (2003) 278(18): 15727-34. doi:10.1074/jbc.M300546200

50. Chen LF, Mu Y, Greene WC. Acetylation of RelA at discrete sites regulates distinct nuclear functions of NF-kappaB. EMBO J (2002) 21(23):6539-48. doi:10.1093/emboj/cdf660

51. Gregoire S, Xiao L, Nie J, Zhang X, Xu M, Li J, et al. Histone deacetylase 3 interacts with and deacetylates myocyte enhancer factor 2. Mol Cell Biol (2007) 27(4):1280-95. doi:10.1128/MCB.00882-06

52. Moser MA, Hagelkruys A, Seiser C. Transcription and beyond: the role of mammalian class I lysine deacetylases. Chromosoma (2014) 123(1-2):67-78. doi:10.1007/s00412-013-0441-x

53. Barchowsky A, Frleta D, Vincenti MP. Integration of the NF-kappaB and mitogen-activated protein kinase/AP-1 pathways at the collagenase-1 promoter: divergence of IL-1 and TNF-dependent signal transduction in rabbit primary synovial fibroblasts. Cytokine (2000) 12(10):1469-79. doi:10.1006/ cyto.2000.0743

54. Kumar D, Ray A, Ray BK. Transcriptional synergy mediated by SAF-1 and AP-1: critical role of N-terminal polyalanine and two zinc finger domains of SAF-1. J Biol Chem (2009) 284(3):1853-62. doi:10.1074/jbc. M806289200

Conflict of Interest Statement: The authors declare that the research was conducted in the absence of any commercial or financial relationships that could be construed as a potential conflict of interest.

Copyright $\odot 2017$ Moores, Brilha, Schutgens, Elkington and Friedland. This is an open-access article distributed under the terms of the Creative Commons Attribution License (CC BY). The use, distribution or reproduction in other forums is permitted, provided the original author(s) or licensor are credited and that the original publication in this journal is cited, in accordance with accepted academic practice. No use, distribution or reproduction is permitted which does not comply with these terms. 